\title{
PET-CT confirms the diagnosis of pyogenic spondylodiscitis complicated by psoas abscess
}

\author{
Jonathan M Davison, ${ }^{1}{ }^{1}$ Jess A Graham, ${ }^{1}$ Neris M Nieves, ${ }^{1}$ Stephen M Yoest ${ }^{1,2}$
}

${ }^{1}$ Department of Radiology, Madigan Army Medical Center, Tacoma, Washington, USA ${ }^{2}$ Department of Radiology, Uniform Services University of the Health Sciences, Bethesda, Maryland, USA

\section{Correspondence to} Dr Jonathan M Davison, jonathan.davison@gmail.com
To cite: Davison JM, Graham JA, Nieves NM, et al. BMJ Case Reports Published online: [please include Day Month Year] doi:10.1136/bcr-2012008264

\section{DESCRIPTION}

The authors report a case of a 64-year-old woman with a history of diabetes mellitus (DM) and haemodialysis dependent end-stage renal disease admitted to the intensive care unit for hypoglycaemia, hyperkalaemia, elevated white blood cell count and elevated inflammatory markers. During the course of her hospitalisation, she complained of persistent low back pain. Although gadolinium contrast agents are generally contraindicated in these patients due to significant risk of nephrogenic systemic fibrosis, lumbar spine MRI with gadopentetate dimeglumine contrast was felt to be absolutely necessary, given the need to confirm spondylodiscitis in order to guide treatment. We adhered to strict departmental protocol with written consent and haemodialysis within hours after the examination. Results showed enhancement of the right L5 pedicle and moderate degenerative disc disease. The findings of right pedicle enhancement were interpreted as non-specific, representing infection or neoplasm. Several days later, an F-18 fluorodeoxyglucose positron emission tomographycomputerised tomography (PET-CT) exam identified spondylodiscitis with a right psoas abscess (figures 1-3), a diagnosis confirmed by methicillin resistant Staphylococcus aureus (MRSA) bacteraemia. Fortunately, in the year since the MRI, the patient has not reported clinical findings to be consistent with nephrogenic systemic fibrosis.

Pyogenic spondylodiscitis is the major manifestation of haematogenous osteomyelitis in patients over the age of 50, preferentially affecting the lumbar spine. ${ }^{1} S$ aureus is the major infective agent,

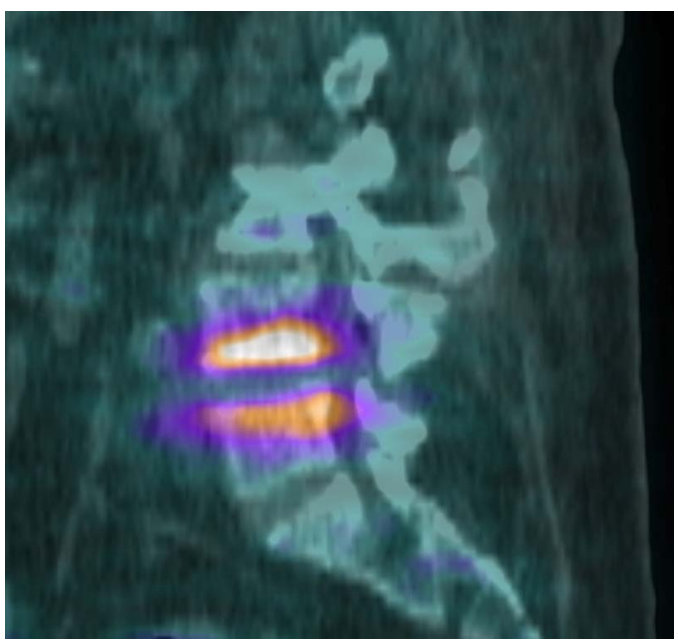

Figure 1 Sagittal fusion PET-CT image of lumbar spine demonstrates abnormal hypermetabolism within the inferior endplate of $L 4$ and superior endplate of $L 5$, suspicious for spondylodiscitis.

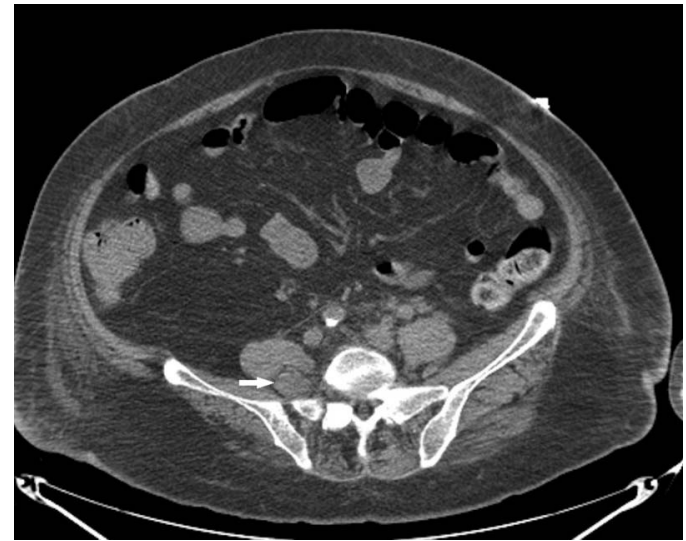

Figure 2 Axial CT image at the $L 5$ vertebral level demonstrates a small fluid collection posterior to the right psoas muscle (arrow).

responsible for greater than $50 \%$ of cases. ${ }^{1} \mathrm{DM}$ is the most common risk factor. ${ }^{1}$

The adult intervertebral disc typically is avascular, therefore the marrow in the region of the vertebral body end plate is usually infected first, with subsequent spread to the disc. ${ }^{1}$ MRI is the imaging modality of choice with an accuracy of $94 \% .^{2}$ Early MRI findings typically include low signal intensity on T1-weighted images in endplate of the affected vertebral body along with contrast enhancement. Further progression usually involves the disc, manifested as high T2 signal. ${ }^{3}$ Pyogenic spinal osteomyelitis rarely involves the posterior elements of the vertebrae. ${ }^{2}$ Paraspinal abscess is a known uncommon complication, usually seen in advanced cases. $^{3}$

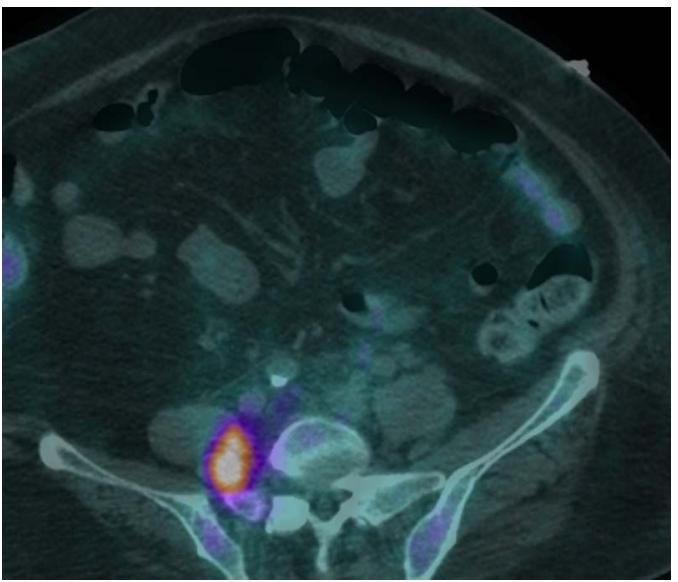

Figure 3 Axial fusion PET-CT image demonstrates abnormal hypermetabolism within the fluid collection posterior to the right psoas muscle compatible with abscess. 
In recent years the role of PET-CT has expanded beyond oncology to include screening evaluation of inflammatory and infectious disorders, such as fevers of unknown origin, prosthetic infections and osteomyelitis. ${ }^{4}$ Several small series have demonstrated a high sensitivity of PET-CT in spondylodiscitis and its ability to differentiate disc infection from endplate degenerative change. ${ }^{3}$ Recent work also demonstrated that PET-CT may help monitor response to therapy in patients with known spondylodiscitis. ${ }^{5}$

Two components of this case made it unique. First, we could not find reference in the literature on PET-CT diagnosing infectious spondylodiscitis complicated by a psoas abscess. Second, while PET-CT has primarily been used as a screening modality, in this case it confirmed the diagnosis, a role primarily relegated to MRI. More investigation may better elucidate its capacity to diagnose spondylodiscitis, particularly in patients in whom MRI or gadolinium-based contrast agents are contraindicated.
Competing interests None.

Patient consent Obtained.

Provenance and peer review Not commissioned; externally peer reviewed.

\section{REFERENCES}

1 Gouliouris T, Aliyu A, Brown N. Spondylodiscitis: update on diagnosis and management. J Antimicrob Chemother 2010;65 (Suppl 3):11-24.

2 James SLJ, Davies AM. Imaging of infectious spinal disorders in children and adults. Eur J Radiol 2006;58:27-40

3 Helms CA, Major NM, Kaplan PA, et al. Musculoskeletal MRI. 2nd edn. Philadelphia, PA: Saunders Elsevier, 2009.

4 Bertagna F, Pizzocaro C, Biasiotto G, et al. 18 F-FDG-PET/CT findings in patients affected by spondylodiscitis. Hell J Nucl Med 2010;13:166-8.

5 Nanni C, Boriani L, Salvadori C, et al. FDG PET/CT is useful for the interim evaluation of response to therapy in patients affected by haematogenous spondylodiscitis. Eur J Nucl Med Mol Imaging 2012;39:1538-44.

\section{Learning points}

- In cases of suspected spondylodiscitis with clinical ambiguity, equivocal MRI findings or those where MRI or gadolinium-based contrast agents are contraindicated, PET-CT may be a reasonable alternative to confirm this diagnosis.

- Diabetic patients with elevated inflammatory markers and low back pain warrant further work-up for pyogenic spondylodiscitis.

Copyright 2013 BMJ Publishing Group. All rights reserved. For permission to reuse any of this content visit http://group.bmj.com/group/rights-licensing/permissions.

BMJ Case Report Fellows may re-use this article for personal use and teaching without any further permission.

Become a Fellow of BMJ Case Reports today and you can:

- Submit as many cases as you like

- Enjoy fast sympathetic peer review and rapid publication of accepted articles

- Access all the published articles

- Re-use any of the published material for personal use and teaching without further permission

For information on Institutional Fellowships contact consortiasales@bmjgroup.com

Visit casereports.bmj.com for more articles like this and to become a Fellow 